\title{
Evaluation of Patients with Head and Neck Cancer by Means of ${ }^{99 m}$ Tc-Glucarate
}

Juan P. Gambini ${ }^{1}$, Margarita Nuñez ${ }^{2}$, Pablo Cabral ${ }^{3}$, Martín Lafferranderie ${ }^{4}$, Javier Noble ${ }^{5}$, Eduardo Corchs ${ }^{5}$, Ricardo D’Albora ${ }^{4}$, Eduardo Savio $^{6}$, Lucía Delgado ${ }^{7}$, and Omar Alonso ${ }^{1,2}$

${ }^{I}$ Nuclear Medicine Center, Clinical Hospital, University of Uruguay, Montevideo, Uruguay; ${ }^{2}$ School of Medical Technology, Nuclear Medicine Technology Program, University of Uruguay, Montevideo, Uruguay; ${ }^{3}$ Nuclear Investigations Center, School of Science, University of Uruguay, Montevideo, Uruguay; ${ }^{4}$ Department of Otorhinolaryngology, Clinical Hospital, University of Uruguay, Montevideo, Uruguay; ${ }^{5}$ Department of Radiology, Clinical Hospital, University of Uruguay, Montevideo, Uruguay; ${ }^{6}$ Department of Radiochemistry, School of Chemistry, University of Uruguay, Montevideo, Uruguay; and ${ }^{7}$ Department of Oncology, Clinical Hospital, University of Uruguay, Montevideo, Uruguay

Preliminary findings have suggested that $99 \mathrm{mTc}$-glucarate has tumor-seeking properties. The purpose of this study was to explore the potential of this tracer to evaluate malignant head and neck tumors by means of SPECT/CT software fusion imaging. Methods: Eleven male patients with advanced head and neck carcinoma were included in the study: 9 with locally advanced disease and 2 with clinical suspicion of local relapse. Scanning

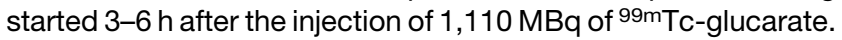
Planar and SPECT images of the head, neck, and thorax were acquired. Three-dimensional images were also coregistered with CT. Results: We found ${ }^{99 m}$ Tc-glucarate uptake in all suspected lesions. SPECT/CT fusion imaging was helpful in all cases for topographically localizing the tracer foci. Conclusion: ${ }^{99 m T c-}$ glucarate can be considered a potential tracer for the evaluation of patients with head and neck tumors.

Key Words: head and neck tumors; $99 \mathrm{~m}$ Tc-glucarate; SPECT/CT software fusion

J Nucl Med Technol 2009; 37:229-232

DOI: $10.2967 /$ jnmt.109.062927

\section{A}

lthough ${ }^{18} \mathrm{~F}$-FDG PET has set a new standard for the evaluation of cancer patients (1), the development of new 99mTc-based SPECT radiopharmaceuticals may become an attractive alternative because of its lower cost and better availability. Glucarate is a 6-carbon dicarboxylic acid, a product of the metabolism of D-glucuronic acid that can

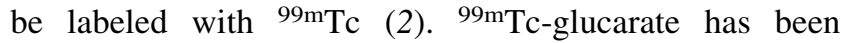
described as an agent avid for acute cerebral injury and myocardial infarction (3-7) and as a possible tumor tracer (8-13). The mechanism involved in uptake of ${ }^{99 \mathrm{~m}} \mathrm{Tc}-$ glucarate by necrotic cells may be related to binding of the

Received Feb. 4, 2009; revision accepted Sep. 15, 2009.

For correspondence or reprints contact: Omar Alonso, Nuclear Medicine Center, Clinical Hospital, University of Uruguay, Avenida Italia $\mathrm{s} / \mathrm{n}$, Montevideo 11600, Uruguay.

E-mail: oalonso@hc.edu.uy

COPYRIGHT @ 2009 by the Society of Nuclear Medicine, Inc. tracer to histones in the cells (14-16). Besides, because of the similarity of ${ }^{99} \mathrm{~m}$ Tc-glucarate to fructose, ${ }^{99} \mathrm{~m} \mathrm{Tc}-$ glucarate enters the cell by this metabolically active sugar transport system (8). Furthermore, Ballinger et al. (17) reported that ${ }^{99 \mathrm{~m}} \mathrm{Tc}$-glucarate showed a 2- to 3-fold enhanced accumulation in hypoxic cells relative to aerobic cells in an in vitro system of cultured ovary fibroblasts.

Malignant tumors arising in the head and neck constitute a diagnostically challenging pathology representing about $3 \%$ of all newly diagnosed cases of cancer in humans (18). The purpose of this study was to explore the potential of 99m Tc-glucarate to evaluate malignant head and neck tumors by means of SPECT. Additionally, SPECT/CT software fusion was performed to increase diagnostic precision.

\section{MATERIALS AND METHODS}

Eleven male patients with advanced head and neck squamous cell carcinoma were included in the study: 9 patients with locally advanced disease enrolled before surgery and 2 patients with clinical suspicion of postsurgical local relapse (Table 1). Imaging was performed at the Clinical Hospital of the University of Uruguay after ethical clearance had been obtained. Before undergoing scintigraphy, all patients had pathologic confirmation of their primary tumors, as well as corresponding conventional imaging examinations. Once written informed consent had been obtained, imaging started 3-6 $\mathrm{h}$ after the injection of $1,110 \mathrm{MBq}$ of ${ }^{99 \mathrm{~m}} \mathrm{Tc}$-glucarate, with a 10-min planar image of the head, neck, and thorax being obtained in a $256 \times 256$ matrix. The images were acquired with a digital $\gamma$-camera equipped with a double-head detector (Nucline Spirit DH-V; Mediso) and low-energy highresolution collimators and connected in series to a dedicated computer (Mirage; Segami Corp.). The SPECT studies were performed immediately afterward, using a $128 \times 128$ matrix, $360^{\circ}, 120$ steps, and $30 \mathrm{~s}$ per step. Images were reconstructed using the ordered-subsets expectation maximization iterative method and a postreconstruction Butterworth filter of fourth order with a cutoff frequency of $0.25-0.35$ Nyquist. Three-dimensional images were also coregistered with $\mathrm{CT}$ to better localize the uptake. CT was performed with a dual-slice Twin Flash scanner 
TABLE 1

Patient Characteristics

\begin{tabular}{|c|c|c|c|c|c|c|c|c|c|}
\hline \multicolumn{8}{|c|}{ Patient } & \multicolumn{2}{|c|}{ 99mTc glucarate } \\
\hline Number & Primary tumor location & $\begin{array}{l}\text { Age } \\
\text { (y) }\end{array}$ & Sex & $\mathrm{pN}$ & $\begin{array}{c}\text { Stage after } \\
\text { surgery of } \\
\text { primary tumor }\end{array}$ & Size $(\mathrm{cm})^{\star}$ & Pathology & $\begin{array}{c}\text { Primary } \\
\text { lesion or } \\
\text { local relapse }\end{array}$ & $\begin{array}{c}\text { Regional } \\
\text { node } \\
\text { involvement }\end{array}$ \\
\hline 1 & Oropharynx cancer & 55 & $\mathrm{M}$ & NO & IV & 5.5 & MDEC & + & - \\
\hline 2 & Supraglottic tumor & 46 & $\mathrm{M}$ & $\mathrm{N} 2 \mathrm{c}$ & IVA & 3.2 & MDEC & + & + \\
\hline 3 & Nasopharynx tumor & 61 & $\mathrm{M}$ & NO & IV & 4.6 & $\begin{array}{l}\text { Undifferentiated } \\
\text { carcinoma }\end{array}$ & + & - \\
\hline 4 & Larynx cancer & 62 & $\mathrm{M}$ & NO & IV & 3.8 & WDEC & + & - \\
\hline 5 & Glottic and supraglottic cancer & 80 & $\mathrm{M}$ & NO & III & 1.8 & WDEC & + & - \\
\hline 6 & $\begin{array}{l}\text { Carcinoma of right retromolar } \\
\text { trigone }\end{array}$ & 57 & $\mathrm{M}$ & N1 & IV & 6.2 & WDEC & + & + \\
\hline 7 & Tonsil cancer & 55 & $\mathrm{M}$ & N1 & IVA & 3.8 & WDEC & + & + \\
\hline 8 & Larynx cancer & 66 & $\mathrm{M}$ & N3 & IV & 3.7 & WDEC & + & + \\
\hline 9 & Right inferior maxillary tumor & 67 & $\mathrm{M}$ & NO & IV & 3.9 & WDEC & + & - \\
\hline 10 & $\begin{array}{l}\text { Right nasogenian fold tumor } \\
\text { (postsurgery) }\end{array}$ & 65 & $\mathrm{M}$ & $\begin{array}{l}\text { Local } \\
\text { relapse? }\end{array}$ & IV & 4.8 & $\begin{array}{l}\text { Sclerosant } \\
\text { basocellular } \\
\text { epithelioma }\end{array}$ & + & - \\
\hline 11 & Oropharynx tumor & 50 & $\mathrm{M}$ & $\begin{array}{l}\text { Local } \\
\text { relapse? }\end{array}$ & IVA & 2.2 & PDEC & + & - \\
\hline
\end{tabular}

*Greatest dimension.

MDEC = moderately differentiated epidermoid carcinoma; WDEC = well-differentiated epidermoid carcinoma; PDEC = poorly differentiated epidermoid carcinoma.

(Elscint), using a 250-mm scan diameter, $120 \mathrm{kV}, 100 \mathrm{mAs} / \mathrm{slice}$, a pitch of $0.7-1$, and a $512 \times 512$ matrix. Intravenous contrast material was used in all cases.

Images were fused using the Mutual Information Registration software available on the Mirage workstation (a fully automated registration method that allows volume alignment by mutual information).

SPECT and CT were performed within 2-5 d of each other and with the patients in the same position to decrease misregistration errors. ${ }^{99 \mathrm{~m}} \mathrm{Tc}$-glucarate was prepared from current good manufacturing practice glucarate formulation kits (School of Chemistry, University of Uruguay). Radiochemical purity was greater than $90 \%$ in all cases.

\section{RESULTS}

We found ${ }^{99 \mathrm{~m}} \mathrm{Tc}$-glucarate uptake in all primary tumors $(n=9)$, in regional lymph node basins $(n=4)$, and in those regions where a local relapse after surgery was suspected $(n=2)$. Furthermore, we did not find significant tracer accumulation in thyroid tissue or in salivary glands. All lesions were confirmed by pathology to have a low to moderate degree of necrosis. Pathologic TNM staging was used to unify pathology findings from different head and neck tumors. Images did not show other areas of abnormal uptake, and there was no clinical or radiologic evidence of distant metastases. SPECT/CT fusion images were of good quality, allowing in all cases good topographic localization of tracer foci (Figs. 1 and 2). Moreover, hybrid images were particularly useful in those patients with imaging findings of local relapse that were further confirmed by pathology after surgery (Fig. 2).

\section{DISCUSSION}

Our results demonstrate the tumor-avid properties of ${ }^{99 m}$ Tc-glucarate in patients with malignant head and neck lesions. All primary and local-relapse lesions were detected with good contrast.

On the basis of our prior findings $(12,13)$, ${ }^{99 \mathrm{~m}} \mathrm{Tc}-$ glucarate could be considered a candidate agent for the detection of malignant lesions in the thorax and in the head and neck. Unlike ${ }^{99 \mathrm{~m}} \mathrm{Tc}$-sestamibi, ${ }^{99 \mathrm{~m}} \mathrm{Tc}$-glucarate does not accumulate in the thyroid and salivary glands and thus allows images of good signal-to-noise ratio. Moreover, this radiopharmaceutical is not affected by the expression of multidrug resistance-associated protein 1 , whereas ${ }^{99 \mathrm{~m}} \mathrm{Tc}-$ sestamibi accumulation in tumor cell lines is inversely proportional to the expression of the cell multidrug resistance phenotype (10).

The mechanisms involved in such uptake could be related to the high metabolic rate of tumors together with hypoxic, necrotic, or apoptotic processes that could dynamically coexist in different proportions within each malignant lesion. The impact of each possible mechanism may play different roles according to the type of lesion (primary, local relapse, lymph node metastases) and lesion size because tracer sensitivity might be limited for tumors smaller than those included in this series.

SPECT/CT software fusion images were helpful to establish the correct anatomic location of ${ }^{99 \mathrm{~m}} \mathrm{Tc}$-glucarate foci. It is well known that SPECT/CT has been used for the evaluation of patients with various malignant tumors with good results (19). The alternative to the more expensive 

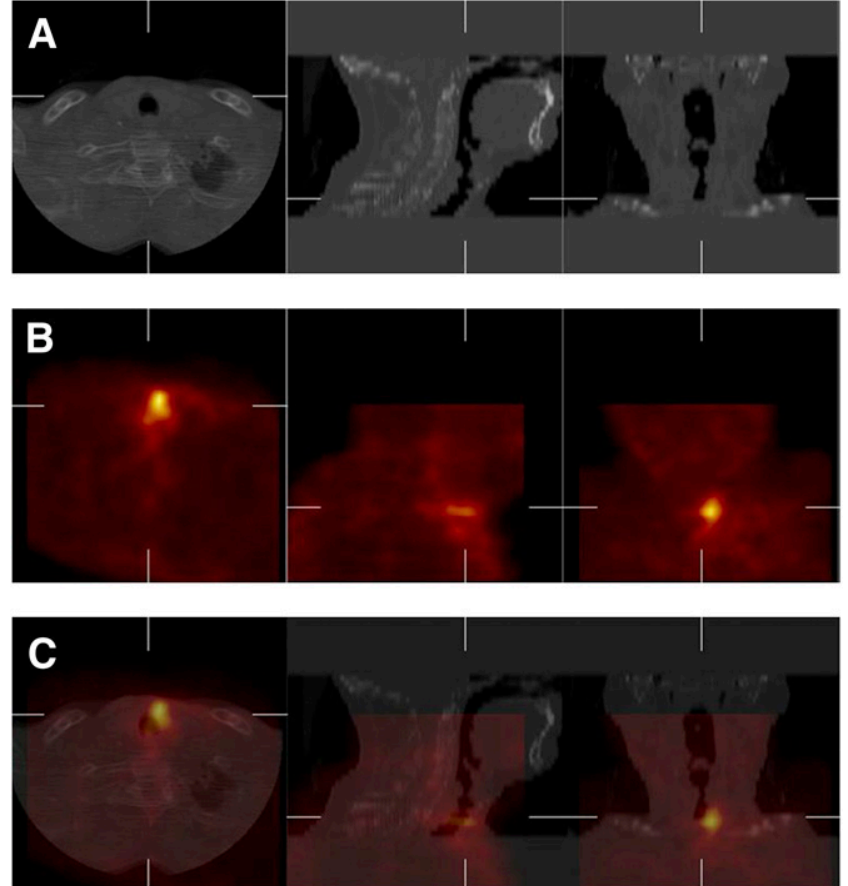

FIGURE 1. A 62-y-old patient with larynx cancer. (A) Head and neck CT image of patient showing transaxial (left), sagittal (middle), and coronal (right) slices. (B) Head and neck $99 \mathrm{mTc}-$ glucarate SPECT image. (C) SPECT/CT fusion image. CT images show thickening of soft tissues of left side of subglottis with eccentricity and luminal stenosis. Fusion images show intense focal uptake in that region.

hybrid SPECT/CT technology is software fusion of CT with SPECT data. In our series, because of the unique anatomic characteristics of the head and neck region, we obtained fused images of good quality without using external markers. Even though this technique is more time-consuming and may have disadvantages related to misregistration, the patient is exposed to less radiation and the imaging can be performed without significant additional costs.

\section{CONCLUSION}

Our preliminary data suggest that ${ }^{99 \mathrm{~m}} \mathrm{Tc}$-glucarate can be considered a potential tracer for the evaluation of patients with head and neck tumors. The good tumor-to-background relation of ${ }^{99 \mathrm{~m}} \mathrm{Tc}$-glucarate allows fusion imaging with CT. These results must be validated in a larger series of patients with an appropriate follow-up.

\section{ACKNOWLEDGMENT}

This work was partially supported by a research grant from the Comisión Sectorial de Investigación Científica (CSIC), University of Uruguay, Montevideo, Uruguay.

\section{REFERENCES}

1. Fletcher JW, Djulbegovic B, Soares HP, et al. Recommendations on the use of ${ }^{18}$ F-FDG PET in oncology. J Nucl Med. 2008;49:480-508.
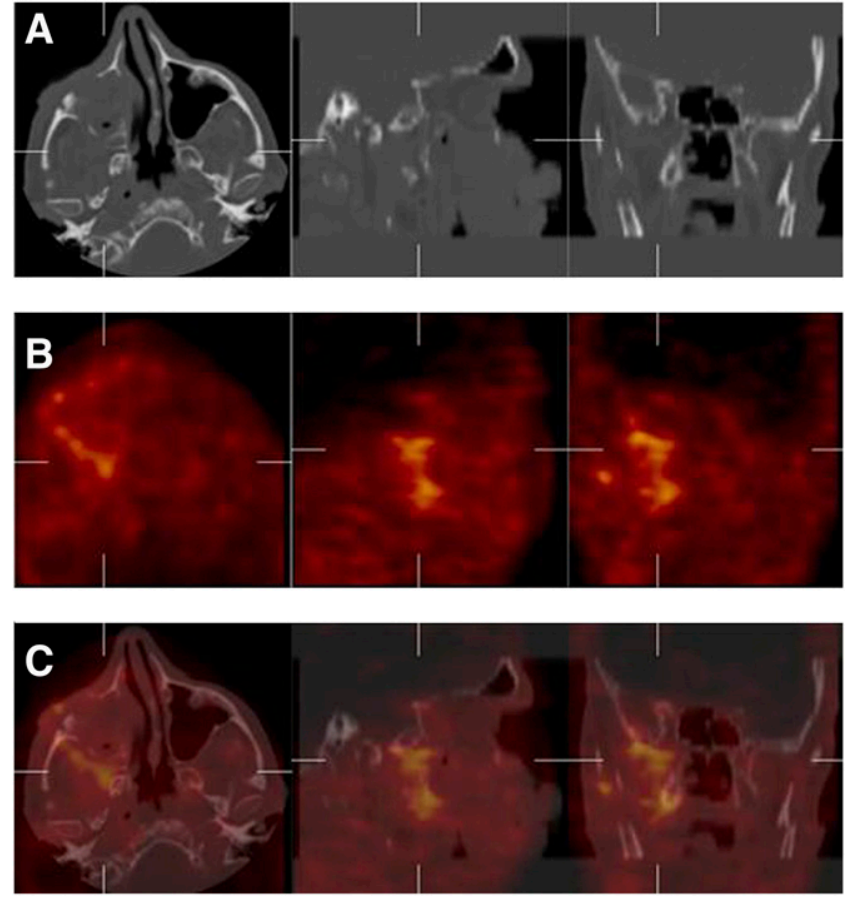

FIGURE 2. A 65-y-old patient with clinical suspicion of local relapse from previously resected sclerosant basocellular epithelioma in right nasogenian fold. Patient underwent right maxillary antrectomy. (A) CT images show surgical sequel at roof of right maxillary sinus with mucosal thickening of cavity. (B and C) ${ }^{99 m T c-g l u c a r a t e ~ s h o w s ~ i n t e n s e ~ u p t a k e ~(B) ~ t h a t ~ i n ~ f u s i o n ~}$ images corresponded to location of pterigomaxilar fossa (C). Lesion was further confirmed as local relapse by biopsy.

2. Ballinger JR, Proulx A, Ruddy TD. Stable kit formation of technetium-99mglucarate. Radiat Appl Instrum Part A. 1991;42:405-406.

3. Yaoita H, Uehara T, Brownell AL, et al. Localization of technetium-99mglucarate in zones of acute cerebral injury. J Nucl Med. 1991;32:272-278.

4. Orlandi C, Crane PD, Edwards DS, et al. Early scintigraphic detection of experimental myocardial infarction in dogs with technetium-99m-glucaric acid. J Nucl Med. 1991;32:263-268.

5. Mariani G, Villa G, Rossettin PF, et al. Detection of acute myocardial infarction by ${ }^{99 \mathrm{~m} T c}$ labeled $\mathrm{D}$ glucaric acid imaging in patients with acute chest pain. J Nucl Med. 1999;40:1832-1839.

6. Okada DR, Johnson G III, Liu Z, et al. Myocardial kinetics of Tc-99m glucarate in low flow, hypoxia, and aglycemia. J Nucl Cardiol. 2003;10:168-176.

7. Liu Z, Barrett HH, Stevenson GD, Furenlid LR, Pak KY, Woolfenden JM. Evaluating the protective role of ischaemic preconditioning in rat hearts using a stationary small-animal SPECT imager and ${ }^{99 \mathrm{~m}}$ Tc-glucarate. Nucl Med Commun. 2008;29:120-128.

8. Ballinger JR, Hsue V, Rauth AM. Accumulation of technetium- $99 \mathrm{~m}$ glucarate: in vitro cell cultures and in vivo tumour models. Nucl Med Commun. 2003;24:597-606.

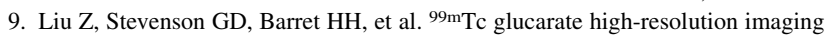
of drug sensitive and drug resistant human breast cancer xenografts in SCID mice. Nucl Med Commun. 2004;25:711-720.

10. Perek N, Le Jeune N, Denoyer D, Dubois F. MRP-1 protein expression and glutathione content of in vitro tumor cell lines derived from human glioma carcinoma U-87-MG do not interact with $99 \mathrm{~m} \mathrm{Tc}$-glucarate uptake. Cancer Biother Radiopharm. 2005;20:391-400.

11. Perek N, Sabido O, Le Jeune N, et al. Can ${ }^{99 \mathrm{~m}} \mathrm{Tc}$-glucarate be used to evaluate tumour necrosis? In vitro and in vivo studies in leukaemic tumour cell line U937. Eur J Nucl Med Mol Imaging. 2008;35:1290-1298.

12. Gambini JP, Cabral P, Santander G, et al. ${ }^{99 \mathrm{~m}} \mathrm{Tc}$-glucarate as a potential novel tracer of lung cancer lesions. Alasbimn J. October 2006;9(34). Available at: http://www2.alasbimnjournal.cl/alasbimn/CDA/sec_b/0,1206,SCID\%253D18543,00. html. Accessed September 28, 2009.

13. Gambini JP, Quinn TP, Nuñez M, et al. Is ${ }^{99 \mathrm{~m}} \mathrm{Tc}$ glucarate a tracer of tumor necrosis? Comparison with ${ }^{18}$ F-FDG-PET in an animal model of breast cancer 
and preliminary clinical experience in oncology patients. Alasbimn J. April 2008;10(40). Available at: http://www.alasbimnjournal.cl/alasbimn/index. php?option $=$ com_content $\&$ task $=$ category\&sectionid $=15 \& \mathrm{id}=69 \&$ Itemid $=$ 147. Accessed September 28, 2009.

14. Rammohan R, Petrov A, Haider N, et al. Subnuclear localization of Tc- $99 \mathrm{~m}$ glucarate in necrotic myocardium [abstract]. J Nucl Med. 1996;37(suppl):175P.

15. Narula J, Petrov A, Pak KY, Sister BC, Khaw BA. Very early noninvasive detection of acute experimental nonreperfused myocardial infarction with ${ }^{99 \mathrm{~m}} \mathrm{Tc}$ labeled glucarate. Circulation. 1997;95:1577-1584.
16. Khaw BA, Rammohan R. Tc-99m glucaric acid targets the nucleoproteins of acutely necrotic myocardium but cannot target myocardial cell death due to apoptosis [abstract]. Circulation. 1999;100:I-310.

17. Casciato DA. Head and neck cancers. In: Parker RG, Rice DH, Casciato DA. Manual of Clinical Oncology. Philadelphia, PA: Lippincott Williams \& Wilkins; 2004:143-161.

18. Buscombe JR, Bombardieri E. Imaging cancer using single photon techniques. Q J Nucl Med Mol Imaging. 2005;49:121-131.

19. Keidar Z, Israel O, Krausz Y. SPECT/CT in tumor imaging: technical aspects and clinical applications. Semin Nucl Med. 2003;33:205-218.

\section{Erratum}

Because of a production error, the "Message from the President" in the September issue was incorrectly attributed to the outgoing president, Mark Wallenmeyer, instead of to the incoming president, Cybil J. Nielsen. We regret the error. 